\section{Comparative study of continuous method and interrupted method of episiotomy in terms of healing of the surgical wound}

\author{
Rahul Khatri*, Bhoomika Jain ${ }^{1}$, Sabrina Mhapankar ${ }^{2}$ and \\ Sushil Kumar ${ }^{3}$
}

\author{
1'Department of Obstetrics and Gynaecology, MGM Medical College and Research Centre, Navi \\ Mumbai, India \\ ${ }^{2}$ Assistant Professor, Department of Obstetrics and Gynaecology, MGM Medical College and \\ Research Centre, Navi Mumbai, India \\ ${ }^{3}$ Professor and HOD, Department of Obstetrics and Gynaecology, MGM Medical College and \\ Research Centre, Navi Mumbai, India
}

\section{Abstract}

Episiotomy is a most commonly performed minor procedure. There are various type of episiotomy suturing, in this study two most common types of episiotomy suturing techniques were compare in terms of healing rate. This study concluded that the continuous method of episiotomy suturing is although faster, cosmetically better and associated with less post-operative pain but it heals significantly better than interrupted method of suturing.

\section{More Information}

*Address for Correspondence: Dr. Rahul Khatri, MGM Medical College and Research Centre, Navi Mumbai, India, Tel: 9725572526; Email: rahul.y.khatri@gmail.com

Submitted: March 17, 2021

Approved: April 19, 2021

Published: April 21, 2021

How to cite this article: Khatri R, Jain B, Mhapankar S, Kumar S. Comparative study of continuous method and interrupted method of episiotomy in terms of healing of the surgical wound. Clin J Obstet Gynecol. 2021; 4: 040-043.

DOI: 10.29328 /journal.cjog. 1001084

Copyright: @ 2021 Khatri $R$, et al. This is an open access article distributed under the Creative Commons Attribution License, which permits unrestricted use, distribution, and reproduction in any medium, provided the original work is properly cited.

Keywords: Episiotomy; Continuous suturing; REEDA Score; Healing of episiotomy

\section{Check for updates}

open Access

\section{Introduction}

Episiotomy is a surgical enlargement of the vaginal orifice by an incision to the perineum during the last part of the second stage of labour. This procedure is performed with sterile scissors or scalpel and requires repair by suturing [1]. Seven different types of episiotomy have been described in the literature, but no standardized practice exists in terms of point of origin, angle of the cut and the length of the incision [2]. The most common types are mediolateral and midline episiotomy incisions.

Eighty-five percent of women who have a spontaneous vaginal birth will have some form of perineal trauma and up to $69 \%$ will need to have sutures $[3,4]$.

Despite this, repair of the perineum continues to be an aspect of childbirth that affects a great number of women and can produce maternal morbidity. The majority of women experience pain of short duration as a result of perineal repair after birth and some continue with long-term problems, such as sexual discomfort [5-8].

In addition to the extent of the trauma, the surgical skill
[9], the type of material used [10], and the suture technique for perineal repair after childbirth can have an important effect on the magnitude and degree of morbidity experienced by women after repair. Complications rely upon severity of the perineal trauma and on effectiveness of treatment. Also type of suturing material, the choice of repair technique, and skills of the operator are the three primary components influence the result of the perineal repair. Type of repairing may affect pain and healing. The best method for episiotomy repair should require less time to perform and less utilization of materials and produces less pain in short and in long term period [11]. Although there are various techniques to close the incision of episiotomy, haemostasis and restoration of anatomical structure of the incision site without additional suture are fundamental aspects of success in all methods. At present, two common methods of repair include continuous and interrupted methods [12].

In this study we have compared healing of two different methods of episiotomy suturing.

\section{Aims and objectives}

Comparison between continuous and interrupted suturing method in terms of healing. 


\section{Materials and methods}

A. Study method

- The Present study is a prospective comparative study which was conducted in MGM Hospital, Kalamboli, Navi Mumbai, India from $1^{\text {st }}$ January 2019 to $31^{\text {st }}$ December 2020 after approval by ethical committee.

B. Number of cases

- A total of 200 cases were selected.

- Eligible patients were randomly allocated into two groups:
1. Continuous method (100)
2. Interrupted method (100).

C. Inclusion criteria

1. Normal vaginal delivery.

2. At term (37 wks $-40 \mathrm{wks})$.

3. Vertex presentation.

D. Exclusioncriteria

1. Third and fourth degree perineal tear.

2. Instrumental vaginal delivery.

3. Previous perineal surgery.

4. Anaemia with hemoglobin level $<9 \mathrm{~g} / \mathrm{dl}$.

5. Diabetes mellitus.

6. Coagulation abnormalities.

7. Postpartum hemorrhage.

8. Breech delivery

9. Patient refusal

- Two Hundred pregnant women with the above selection criteria who had an Episiotomy in the second stage of labor in MGM Hospital was chosen to participate in the study after obtaining consent. They were randomly allocated into two groups one group with continuous Episiotomy sutures and another with interrupted sutures. Period of study is 2 years. All patients in both groups signed consent of approval to participate in this study. Women was placed in the dorsal position for repair: The standard analgesia for perineal repair was infiltration analgesia in the wound area using lignocaine $2 \%$. The standard suture material in the study was Vicryl Rapid 2.0.

- Suturing technique

1. Interrupted suturing
- Parts cleaned and draped.

- Proper visualization of apex is visualized, first stich is started $1 \mathrm{~cm}$ above the apex,

- Vaginal epithelium is approximated in a continuous locking manner up to a fourchette and ended with surgical knots.

- Re-approximation of the bulbospongiosus and superficial transverse perineal muscles during restoration of the perineal body is done with 3-4 simple sutures. Figure of 8 sutures can be taken to achieve hemostasis.

- Hemostasis achieved

- Skin is approximated using 4-5 vertical mattress sutures.

2. Continuous Suturing

- Parts cleaned and draped.

- Proper visualization of the apex is visualized, the first stitch is started $1 \mathrm{~cm}$ above the apex,

- Vaginal epithelium approximated in a continuous locking manner up to the fourchette, and entered into the muscular layer.

- Re-approximation of the bulbospongiosus and super ficial transverse perineal muscles during restoration of the perineal body is done with continuous non-locking manner. Up to the apex of skin.

- Skin is approximated in a subcuticular manner from below upwards and the suture is tied with a surgical knot at fourchette and the episiotomy is completed in a single continuous suturing.

The final outcome will be studied on Day 1, Day 2 and Day 3 of delivery by Reeda Scoring method (SHORT TERM).

\section{Results}

Statistical analysis of the data collected is as follows, where group A is Interrupted method of suturing group and group B is continuous method of suturing.

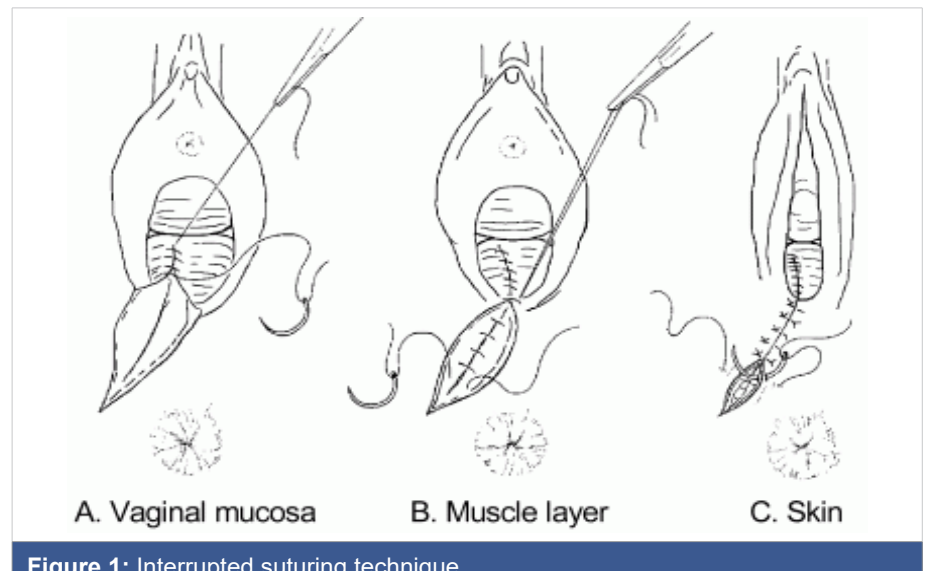



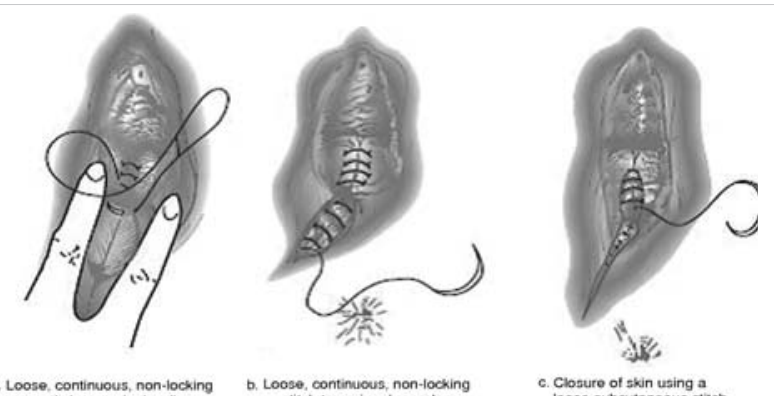

$\begin{aligned} & \text { a. Loose. continuous, non-locking } \\ & \text { ttitch to vaginal wall }\end{aligned}$
b. Loose, continuous, non-locking
stich to perineal muscles c. Closure of skin using a
loose subcutaneous stich

\section{Figure 2: Continuous suturing technique.}

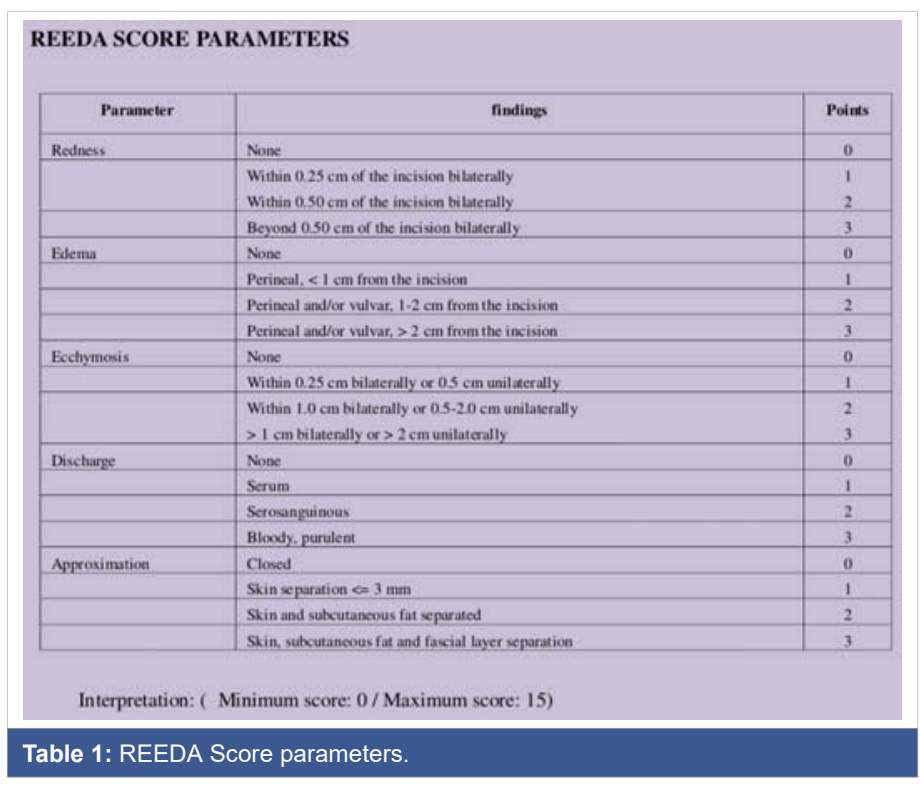

Age:

Most of the patients were primi gravida in both the study group with $46 \%$ in group A and $39 \%$ in group B. While $35 \%$ were $2^{\text {nd }}$ gravida in group A and $36 \%$ in group B. $12 \%$ were $3^{\text {rd }}$ gravida in group A while $19 \%$ in group B. $6 \%$ and $5 \%$ were $4^{\text {th }}$ gravida in group A and group B respectively. Only $1 \%$ were $5^{\text {th }}$ gravida in both the groups.

Gestational Age:

Mean gestational age in group A was 38.23 weeks, and in group B it was 38.48 weeks.

\section{REEDA Score:}

Descriptive Statistics:

Test of Normality:

Interpretation: $p$ - value less than that of 0.05 indicates that data is not distributed normally.

\begin{tabular}{|c|c|c|c|}
\hline & Group A & Group B \\
\hline \multicolumn{2}{|c|}{ Mean } & 24.45 & 24.66 \\
\hline \multicolumn{2}{|c|}{ Standard Deviation } & 4.25 & 4.54 \\
\hline & $t$ - test value & d.f. & $p$-value \\
\hline Age & -.338 & 198 & .736 \\
\hline
\end{tabular}

Table 2: Gravidty wise distribution in study group, mean and tests applied on gravidity of study population.

\begin{tabular}{|c|c|c|c|c|}
\hline \multirow{2}{*}{ Gravida } & \multicolumn{2}{|c}{ Group A } & \multicolumn{2}{c|}{ Study Group } \\
\hline & Count & $\%$ & Count & $\%$ \\
\hline 1 & 46 & $46.0 \%$ & 39 & $39.0 \%$ \\
\hline 2 & 35 & $35.0 \%$ & 36 & $36.0 \%$ \\
\hline 3 & 12 & $12.0 \%$ & 19 & $19.0 \%$ \\
\hline 4 & 6 & $6.0 \%$ & 5 & $5.0 \%$ \\
\hline 5 & 1 & $1.0 \%$ & 1 & $1.0 \%$ \\
\hline & Study Group & Mean & Std. Deviation \\
\hline \multirow{2}{*}{ Gravidity } & Group A & 1.8100 & \multicolumn{2}{|c|}{.93954} \\
\hline & Group B & 1.9300 & \multicolumn{2}{c|}{.93479} \\
\hline & $t$ - test value & d.f. & \multicolumn{2}{|c|}{$p-$ value } \\
\hline
\end{tabular}

Table 3: Gestational age mean and tests applied on Gestational age of study population.

\begin{tabular}{|c|c|c|c|}
\hline & \multicolumn{2}{|c|}{ Study Group } \\
\hline \multicolumn{2}{|c|}{ Mean } & Group A & Group B \\
\hline Standard Deviation & 38.23 & 38.48 \\
\hline & $t-$ test value & 4.14 & 4.15 \\
\hline Gestational Age & -.437 & d.f. & $p-$ value \\
\hline
\end{tabular}

\begin{tabular}{|c|c|c|c|}
\hline \multicolumn{2}{|c|}{} & \multicolumn{2}{c|}{ Study Group } \\
\cline { 2 - 4 } & Group A & Group B \\
\hline \multirow{2}{*}{ Day 1 } & Mean & 3.60 & 3.07 \\
\cline { 2 - 4 } & Standard Deviation & 1.10 & 1.11 \\
\hline \multirow{2}{*}{ Day 2 } & Mean & 2.90 & 2.47 \\
\cline { 2 - 4 } & Standard Deviation & 1.02 & 1.10 \\
\hline \multirow{2}{*}{ Day 3 } & Mean & 2.19 & 1.83 \\
\cline { 2 - 4 } & Standard Deviation & 1.04 & 1.13 \\
\hline
\end{tabular}

\begin{tabular}{|c|c|c|c|c|}
\hline \multirow{2}{*}{} & \multirow{2}{*}{ Study Group } & \multicolumn{3}{|c|}{ Kolmogorov-Smirnov } \\
\cline { 2 - 5 } & & Statistic & $\mathbf{d f}$ & Sig. \\
\hline \multirow{2}{*}{ Day 1 } & Group A & .227 & 100 & .000 \\
\cline { 2 - 5 } & Group B & .198 & 100 & .000 \\
\hline \multirow{2}{*}{ Day 2 } & Group A & .191 & 100 & .000 \\
\hline \multirow{2}{*}{ Day 3 } & Group B & .206 & 100 & .000 \\
\hline & Group A & .212 & 100 & .000 \\
\hline & Group B & .189 & 100 & .000 \\
\hline
\end{tabular}

Mann-Whitney U test Comparison of REEDA Score:

Interpretation: Since $p$ - value is less than that of 0.05 indicates that the average score of Group A and Group B differ significantly. The average score in Group A is significantly more than Group B.

Interpretation: Since $p$ - value is less than that of 0.05 indicates that the average score of group A and group B differ significantly on all three days, Day 1, 2 and 3. The average score in group A is significantly more than group B.

\section{Discussion}

In our study, we have attempted to compare the results of the two different episiotomy techniques i.e., continuous method and interrupted method. This study is aimed to determine the efficacy of the two methods in terms of healing.

This study was done on 200 participants over a span of 


\begin{tabular}{|c|c|c|c|}
\hline Table 4: REEDA Score on day 1,2 and 3 in study population, mean and tests applied. \\
\hline & Day-1 & Day-2 & Day-3 \\
\hline Mann-Whitney U & 3908.500 & 3970.000 & 4177.000 \\
\hline Wilcoxon W & 8958.500 & 9020.000 & 9227.000 \\
\hline$Z$ & -2.780 & -2.616 & -2.086 \\
\hline$p$ - value & .005 & .009 & .037 \\
\hline
\end{tabular}

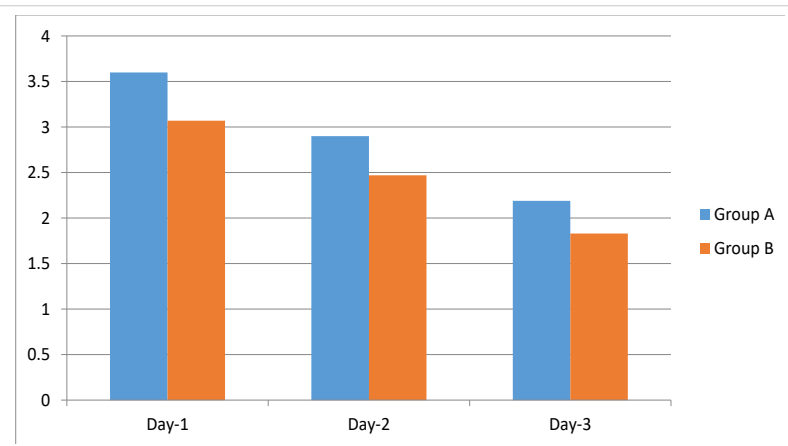

Figure 3: REEDA Score on day 1, 2 and 3 in study population.

two years. Following are the observations from our study and a correlation with studies conducted in the past in medical literature.

A comparison was done between the age of the patients among the two study groups. The mean age in Group A was 24.45 years whereas in Group B was 24.66 years. The $p$ - value being 0.736 . The difference was considered to be statistically not significant.

These findings are similar to studies conducted by Samal, et al. [13], Mahmoud, et al. [14], Martínez-Galiano, et al. [15] where age of the patients undergoing episiotomy was statistically not significant.

Mean Gravidity in group A and Group B is 1.81 and 1.93 respectively. $p$ - value being 0.366 which is statistically not significant.

A comparison was done between the gestational age at delivery between the two study groups. The mean gestational age in Group A was 38.23 and that in Group B was 38.48. $p$ - value was 0.663 . The difference was considered to be statistically not significant.

These findings are similar to the study conducted by Martínez-Galiano, et al. [15] where gestational age of the patients undergoing episiotomy was statistically not significant.

In our study, the mean REEDA score for healing of episiotomy in group A on day 1 was 3.60, Day 2 was 2.90, and Day 3 was 2.19: Mean REEDA score in Group B on Day 1 was 3.07, day 2 was 2.47 , day 3 was 1.83, with $p$ - value on Day 1, 2, and 3 being $0.005,0.009$, and 0.037 respectively which was significant.

Similar studies done by Nagure, et al. [16] showed a mean value of REEDA score of 3.6 with continuous group and 4.5 with interrupted group on day 3 with a $p$ - value 0.000 which was found significant.

\section{Conclusion}

Hence from this study results continuous suturing heals better.

We recommend continuous suturing method as a routine procedure for episiotomy suturing with 'vicryl rapid' as a routine procedure.

\section{References}

1. Thacker SB, Banta HD. Benefits and risks of episiotomy: An interpretative review of the english language literature, 1860-1980. Obstet Gynecol Sur. 1983; 38: 322-338.

2. Kalis V, Laine $\mathrm{K}$, de Leeuw J, Ismail K, Tincello D. Classification of episiotomy: towards a standardisation of terminology. BJOG An Int J Obstet Gynaecol. 2012;119: 522-526.

PubMed: https://pubmed.ncbi.nlm.nih.gov/22304364/

3. Kettle C, Tohill S. Perineal care. BMJ Clin Evid. 2008; 1401. PubMed: https://pubmed.ncbi.nlm.nih.gov/19445799/

4. Smith LA, Price N, Simonite V, Burns EE. Incidence of and risk factors for perineal trauma: A prospective observational study. BMC Pregnancy Childbirth. 2013; 13: 59.

PubMed: https://pubmed.ncbi.nlm.nih.gov/23497085/

5. Sleep J, Grant A. West Berkshire perineal management trial: Three year follow up. Br Med J (Clin Res Ed). 1987; 295: 749-751. PubMed: https://www.ncbi.nlm.nih.gov/pmc/articles/PMC1247773/

6. Klein MC, Gauthier RJ, Robbins JM, Kaczorowski J, Jorgensen SH, et al Relationship of episiotomy to perineal trauma and morbidity, sexual dysfunction, and pelvic floor relaxation. Am J Obstet Gynecol. 1994; 171: $591-598$

PubMed: https://pubmed.ncbi.nlm.nih.gov/8092203/

7. Glazener CMA, Abdalla M, Stroud P, Templeton A, Russell IT, et al Postnatal maternal morbidity: extent, causes, prevention and treatment. BJOG An Int J Obstet Gynaecol. 1995; 102: 282-287.

PubMed: https://pubmed.ncbi.nlm.nih.gov/7612509/

8. Karaçam Z, Eroğlu K. Effects of episiotomy on bonding and mothers health. J Adv Nurs. 2003; 43: 384-394.

PubMed: https://pubmed.ncbi.nlm.nih.gov/12887357/

9. Tincello DG, Williams A, Fowler GE, Adams EJ, Richmond DH, et al Differences in episiotomy technique between midwives and doctors BJOG. 2003; 110: 1041-1044.

10. McElhinney BR, Glenn DR, Dornan G, Harper MA. Episiotomy repair: Vicryl versus Vicryl rapide. Ulster Med J. 2000; 69: 27-29.

PubMed: https://www.ncbi.nlm.nih.gov/pmc/articles/PMC2449154/

11. Valenzuela $\mathrm{P}$, Saiz Puente MS, Valero JL, Azorín R, Ortega R, et al Continuous versus interrupted sutures for repair of episiotomy or second-degree perineal tears: A randomised controlled trial. BJOG An Int J Obstet Gynaecol. 2009; 116: 436-441.

PubMed: https://pubmed.ncbi.nlm.nih.gov/19187377/

12. Cunningham FG, Lenevo KJ, Bloom SL, Hauth JC, Rouse DJ, et al Williams obstetrics. 2020.

PubMed: https://www.ncbi.nlm.nih.gov/nImcatalog/101626979

13. Samal SK, Rathod S. Comparative analysis of continuous and interrupted suturing techniques for repair of episiotomy or second degree perineal tear. Int J Reprod Contraception, Obstet Gynecol. 2017; 6: 1002.

14. Soliman L, Ghareeb M, Abd Elhameid A, Lashin M. Interrupted Versus Continuous Suturing of Episiotomy: a Comparative Study. Zagazig Univ Med J. 2020; 26: 287-296.

15. Martínez-Galiano JM, Arredondo-López B, Molina-Garcia L, CámaraJurado AM, Cocera-Ruiz E, et al. Continuous versus discontinuous suture in perineal injuries produced during delivery in primiparous women: A randomized controlled trial. BMC Pregnancy Childbirth. 2019; 19: 499 PubMed: https://pubmed.ncbi.nlm.nih.gov/31842788/

16. Nagure AG, Chacko V, Umashankar KM, Saleem MDM. Continuous vs interrupted sutures for the repair of episiotomy: A comparative study. 2002; 8: 1131-1137. 